\title{
Use of mobile telemedicine for cervical cancer screening of HIV-positive women in Gaborone, Botswana
}

\author{
Rachel H Gormley ${ }^{1}$, Kelly E Quinley ${ }^{1}$, Ting Shih² ${ }^{2}$ Zsofia Szep ${ }^{3}$, Ann Steiner ${ }^{4}$, Doreen Ramogola-Masire ${ }^{5}$, \\ Carrie L Kovarik ${ }^{3,6^{*}}$ \\ From $12^{\text {th }}$ International Conference on Malignancies in AIDS and Other Acquired Immunodeficiencies \\ (ICMAOI)
}

Bethesda, MD, USA. 26-27 April, 2010

\section{Introduction and aims}

Throughout the developing world, delivery of women's health care, specifically cervical cancer screening, is limited by cost and access to trained personnel. Visual inspection with application of $4 \%$ acetic acid (VIA) is a practical, inexpensive alternative to cytology-based screening in areas where resources are limited. Mobile telemedicine using a cellular phone to photograph the cervix after VIA allows clinicians in "see and treat" cervical cancer screening clinics to capture high-quality images of the cervix, which can then be transmitted through the cellular network to a gynecology specialist located remotely. We present results of a prospective case-control study evaluating the accuracy of offsite (remote) expert diagnosis using mobile telemedicine photographic images of the cervix with VIA (PIA) in HIV-positive women in Gaborone, Botswana.

\section{Methods and design}

ClickDiagnostics has developed software (ClickDoc) specifically for remote diagnosis with the Samsung Soul U900 phone, which comes equipped with a 5 Megapixel camera. Ninety-five women presenting to Bontleng Clinic were enrolled and had (1) VIA evaluation by an onsite clinician, (2) an HPV (human papillomavirus) sample taken for PCR (polymerase chain reaction), (3) cervical photos taken with the Samsung phone camera, and (4) photos evaluated by original onsite clinician and by a remote gynecology specialist blinded to the initial

\footnotetext{
*Correspondence: carrie.kovarik@uphs.upenn.edu

${ }^{3}$ Department of Medicine, Division of Infectious Diseases, University of

Pennsylvania Medical Center, Philadelphia, PA, USA

Full list of author information is available at the end of the article
}

visit. VIA and PIA results were categorized as "positive," "negative," or "indeterminate." Percent agreement will be calculated for each pair of diagnostic impressions: (1) offsite gynecologist PIA to onsite clinician using VIA, (2) onsite clinician PIA to the same onsite clinician using VIA, (3) offsite gynecologist PIA to onsite clinician PIA. The HPV PCR results will also be compared to VIA findings of the onsite clinician and the PIA findings of the offsite gynecologist.

\section{Results}

All 95 subjects have been enrolled and final data analysis is currently under way. Preliminary concordance data will be presented, along with HPV correlation and prevalence data from PCR testing. We hypothesize that there will be significant concordance in the diagnosis of cervical lesions in HIV patients, when comparing the diagnosis of the onsite clinician to the diagnosis of the clinician evaluating the photos through telemedicine.

\section{Conclusions}

Women in sub-Saharan Africa often present with advanced cervical cancer, which is a result of poor screening, lack of appropriate referral, and HIV-HPV co-infection. In order to improve the availability of cervical cancer screening in Botswana, we propose the use of mobile telemedicine as an adjunct tool to visual screening techniques for cervical cancer. We aim to show that mobile telemedicine technology is a reliable method for diagnosing cervical lesions compared to in-person gynecological evaluation and that use of this technology has the potential to connect resource-poor cancer screening centers to remotely located gynecologists. 


\section{Acknowledgements}

This article has been published as part of Infectious Agents and Cancer Volume 5 Supplement 1, 2010: Proceedings of the $12^{\text {th }}$ International Conference on Malignancies in AIDS and Other Acquired Immunodeficiencies (ICMAOI). The full contents of the supplement are available online at http://www.biomedcentral.com/1750-9378/5?issue=S1

\section{Author details}

'University of Pennsylvania School of Medicine, Philadelphia, PA, USA. ${ }^{2}$ Click Diagnostics, Boston, MA, USA. ${ }^{3}$ Department of Medicine, Division of Infectious Diseases, University of Pennsylvania Medical Center, Philadelphia, PA, USA. ${ }^{4}$ Department of Obstetrics and Gynecology, University of Pennsylvania Medical Center, Philadelphia, PA, USA. ${ }^{5}$ Botswana-UPenn Partnership, Women's Health Initiative, Gaborone, Botswana. ${ }^{6}$ Department of Dermatology, University of Pennsylvania Medical Center, Philadelphia, PA, USA

Published: 11 October 2010

doi:10.1186/1750-9378-5-S1-A86

Cite this article as: Gormley et al: Use of mobile telemedicine for cervical cancer screening of HIV-positive women in Gaborone,

Botswana. Infectious Agents and Cancer 2010 5(Suppl 1):A86.

\section{Submit your next manuscript to BioMed Central} and take full advantage of:

- Convenient online submission

- Thorough peer review

- No space constraints or color figure charges

- Immediate publication on acceptance

- Inclusion in PubMed, CAS, Scopus and Google Scholar

- Research which is freely available for redistribution

Submit your manuscript at www.biomedcentral.com/submit 